\title{
Descriptive functional analysis of challenging behaviours shown by adults with acquired brain injury.
}

\author{
Rahman, B., Oliver, C. and Alderman, N. \\ Cerebra Centre for Neurodevelopmental Disorders, \\ School of Psychology, \\ University of Birmingham
}

Please use this reference when citing this work:

Rahman, B., Oliver, C. and Alderman, N. (2010). Descriptive functional analysis of challenging behaviours shown by adults with acquired brain injury. Neuropsychological Rehabilitation, 20, 212-238. (DOI: 10.1080/09602010903021097)

The Cerebra Centre for Neurodevelopmental Disorders, School of Psychology, University of Birmingham, Edgbaston, Birmingham, B15 2TT

Website: www.cndd.Bham.ac.uk E-mail: cndd-enquiries@contacts.bham.ac.uk 


\begin{abstract}
The neurorehabilitation field has been slow to embrace the practice of functional analysis prior to behavioural intervention. In this study we employed a descriptive functional analytic assessment using continuous recording techniques facilitated by observational software. The aim was to explore whether challenging behaviours shown by nine ABI survivors were socially mediated. Analyses appraised the likelihood of challenging behaviours and environment events occurring concurrently and in sequence to test if a mutual social reinforcement hypothesis was applicable. All nine participants exhibited at least one behaviour that was socially reinforced. Across all participants, $88 \%$ of challenging behaviours showed a significant concurrent association with an environmental event. A demand escape function was identified for twelve behaviours and an attention maintained function in thirteen. The complete behavioural repertoire of three participants served the same function. Five participants presented challenging behaviours with multiple functions. Only $8 \%$ of the concurrent analysis results were not corroborated by the sequential analysis. The findings indicate that challenging behaviours shown by these nine ABI survivors adhered to a social model of reinforcement and were functional. It is suggested that formal functional assessments within the field of neurorehabilitation may lead to better treatment outcomes.
\end{abstract}




\section{ACKNOWLEDGEMENTS}

This study was jointly funded by the University of Birmingham, UK, and St. Andrew's Healthcare, Northampton, UK. The role of the second observer was carried out predominantly by Jenny Churchley. The authors are greatly appreciative of her invaluable assistance and enthusiastic support. 
Descriptive Functional Analysis of Challenging Behaviours Shown by Adults with Acquired

\section{Brain Injury}

Challenging behaviours exhibited by those with acquired brain injury (ABI) are significant obstacles to achieving successful rehabilitative outcomes. Neurobehavioural rehabilitation may be impeded by behavioural excesses such as physical and verbal aggression, self-injury, agitation or sexually inappropriate behaviours (Wood \& Worthington, 2001). Such problematic behaviours can be decreased and managed by adopting a treatment approach based on principles of operant conditioning. This approach is characterised by the systematic assessment of the environmental conditions that precipitate challenging behaviours, as well as the social, perceptual and material stimuli that reinforce challenging behaviours. In this way, the functional implications of a challenging behaviour can be appraised, i.e. what purpose does a behaviour serve, does it fulfil a communicative role and how is it reinforced? Information derived from a functional analysis can then be used to design appropriate intervention strategies, which typically involve the manipulation of existing behavioural contingencies or the introduction of new ones. Therefore, an accurate assessment of behavioural function is required to devise an effective programme of behaviour change (Repp, Felce, \& Barton, 1988).

According to operant theories, any combination of three reinforcement contingencies can motivate (challenging) behaviour: social-positive reinforcement, social-negative reinforcement or automatic reinforcement (Carr, 1977). The positive reinforcement hypothesis states that behaviours are maintained by the contingent delivery of environmental reinforcers. These controlling variables may be social attention or tangible items, such as food, favoured objects or preferred activities (Mace, Page, Ivancic, \& O'Brien, 1986; Day, Rea, Schussler, Larsen, \& Johnson, 1988; Kodak, Northup, \& Kelley, 2007). The negative reinforcement 
hypothesis states that behaviours serve to remove, postpone or reduce aversive stimuli.

Although the aversiveness of a stimulus is idiosyncratic, the contingency is usually conceptualised in terms of escape from instructional task demands or escape from social contact (Carr, Newsom, \& Binkoff, 1980; Repp et al., 1988; Iwata, Pace, Kalsher, Cowdery, \& Cataldo, 1990; Zarcone, Iwata, Hughes, \& Vollmer, 1993). Automatic reinforcement refers to non-environmental operant mechanisms that maintain behaviours. Such reinforcing stimuli are internal and may occur through a process of perceptual feedback (Lovaas, Newsom, \& Hickman, 1987), modulation of arousal (Guess \& Carr, 1991) or pain attenuation (Sandman \& Hetrick, 1995).

Applied behaviour analysis has been well established in the areas of autism, developmental disorder and intellectual disability (Emerson, 2001). However, the neurorehabilitation field has been slow to embrace the practice (Mozzoni, 2000), despite strong calls for the management of ABI to be driven by an integrated model of behaviour analysis (Yody et al., 2000). Although behavioural treatment models have been applied successfully for ABI survivors (Corrigan \& Bach, 2005), particularly those with moderate to severe injuries (Wood, 1987), clinical interventions based on prior functional assessments still remain limited (Ager \& O'May, 2001). Many of the functional assessments conducted in the ABI literature have adopted an experimental methodology (Iwata, Dorsey, Slifer, Bauman, \& Richman, 1982; 1994). Experimental functional analysis involves the systematic manipulation of environmental conditions in an artificial setting, to identify the variables that control and maintain challenging behaviours. Experimental control is deemed to be evident when a change in condition brings an associated change in behaviour.

Although generally considered superior to other functional assessment methods, experimental functional analysis has known disadvantages and conceptual, ethical and practical limitations (Durand \& Crimmins, 1988; Halle \& Spradlin, 1993; Lerman \& Iwata, 
1993). The analogous testing conditions may not match the contingencies operating in the natural environment. Also the sequence and timing of the analogue manipulations may inadvertently influence the likelihood of target behaviours being evoked (Higgins Hains \& Baer, 1989). Furthermore the methodology can only demonstrate a behaviour's responsiveness to a general class of reinforcement but it cannot highlight the specific reinforcers (Oliver, 1991). There are ethical concerns relating to the purposeful presentation of discriminative stimuli and establishing operations, and the potential risk of exposing the challenging behaviour to additional reinforcement processes (Iwata, Vollmer, \& Zarcone, 1990). Finally, the practical issues are the time, resources and expertise required to conduct an experimental functional analysis.

Review of functional analytic studies in the ABI literature population reveals that the majority has focused only on a single target behaviour (Pace, Ivancic, \& Jefferson, 1994; Fyffe, Kahng, Fittro, \& Russell, 2004; Dixon et al., 2004). Only one study has investigated multiple topographies of challenging behaviour (Treadwell \& Page, 1996). However, in this case the topographies were amalgamated into one variable and it has been argued that interpretations of function based on an aggregated variable should be made with caution (Derby et al., 1994; 2000). The absence of analyses of the relationships between behaviours within a repertoire means there is little information on the structure and organisation of challenging behaviours in the ABI population.

Functional assessments in neurorehabilitation settings are typically conducted using descriptive analysis methodology. A descriptive analysis involves direct observation of naturally occurring events. This analysis generates an account of the empirical relationships between behaviours and their antecedents and consequences (Edelson, Taubman, \& Lovaas, 1983; Hall \& Oliver, 1992; Repp \& Karsh, 1994a). Reinforcement contingencies can be inferred on the basis of significant associations between behaviours and environmental events 
(Mace, Lalli, \& Pinter-Lalli, 1991; Lalli, Browder, Mace, \& Brown, 1993; Lerman et al., 1993). A descriptive analysis lacks experimental rigour since behavioural functions are deduced from correlational data. However, it is an efficient form of functional assessment for clinical settings and provides a method of analysing naturally occurring streams of behaviour.

Various forms of descriptive assessments have been conducted with ABI survivors that contrast in terms of the quality of information yielded. Response scatter-plots have been used to provide an event based narrative of the contexts surrounding target behaviours (Persel, Persel, Ashley, \& Krych, 1997). The influence of a restraining stimulus with young people has been gauged using retrospective incident records (Luiselli, Pace, \& Dunn, 2003). The Overt Aggression Scale - Modified for Neurorehabilitation (Alderman, Knight, \& Morgan, 1997) has been applied as an account of the antecedents and consequences of aggressive behaviours. Behaviour-recording charts have been used to formulate management plans for elopement (Yody et al., 2000). The data collection methods in all these treatment studies were intended for use in neurorehabilitation settings. However, for clinicians to collect data alongside their normal duties implies a delay between the occurrence and record of an event. The validity of assessment data may be compromised by recall effects and recording biases, particularly in the case of retrospective methods. Furthermore any account of antecedent and consequent events may be influenced by subjective interpretations and restricted to those occurring contiguous with the target behaviour. All pen-and-paper recording techniques inhibit the possibility of conducting a comprehensive descriptive analysis. The output is constrained in terms of detail as only a limited number of variables can be coded manually. Also the dependent measures are expressed in terms of frequencies only (Luiselli, Dunn, \& Pace, 2005), which makes statistical approaches to function unworkable.

A more fine grained assessment of function can be provided by conducting continuous recordings of events. The superior methods of descriptive analysis are those that 
use electronic technology to record and analyse data (Repp, Harman, Felce, Vanacker, \& Karsh, 1989). Multiple variables can be coded simultaneously and the coding of events is not limited to a small window either side of the target behaviour. Using these observational data, a very detailed analysis of behavioural sequences and environmental correlates across an extended time frame can be undertaken. Although such methods of descriptive analysis have been increasingly applied in the literature on challenging behaviour in intellectual disability, to date no study has used a comprehensive observational technique to conduct a functional assessment with the ABI population.

In this study, a descriptive analysis of frequent and clinically significant challenging behaviours exhibited by ABI survivors shall be conducted. The observations shall take place in the natural environment. All responses will be recorded live on a handheld computer using observational software (Martin, Oliver, \& Hall, 2001). Specific forms of behaviours shall be recorded as distinct units. This novel feature of the study will enable the analyses to be conducted in terms of the individual behaviour form (e.g. kicking, punching) in addition to the topography (e.g. physical aggression). The findings shall not be limited by combining topographies to form an aggregated challenging behaviour variable.

The study seeks to explore whether challenging behaviours presented by adults with $\mathrm{ABI}$ are reinforced by socially mediated contingencies and, hence, are functional. The objectives of the study will be achieved in two stages. The first aim will be to analyse the concurrent associations between challenging behaviours and environmental events. Significant co-occurrences shall be interpreted to ascertain the most probable antecedent of the behaviour and, on this basis, to derive a possible behavioural function. The second aim will be to examine the sequential relationships between challenging behaviours and the relevant social stimulus. Sequential analyses shall be conducted to examine whether a mutual 
reinforcement hypothesis is applicable, by way of verification of the preceding concurrent analysis results.

\section{METHOD}

\section{Participants}

Participants were recruited from a high-dependency ward of a specialist neurobehavioural rehabilitation unit for adults with ABI. Those who presented behaviours that substantially hindered their therapeutic care were eligible to participate. This selection criterion was determined in consultation with staff. Fifteen participants were recruited initially but the recordings were terminated prematurely in six cases. Two participants exhibited considerable reactivity to the observations, two chose to withdraw from the study and two exhibited behaviours too infrequently for any meaningful analysis to be conducted. Demographic details for the nine remaining participants are presented in Table 1. All participants understood simple language and most were able to speak $(1,4,6,8,9)$. Four participants were physically mobile $(2,4,5,9)$ but only two were capable of self-care $(4,9)$. [Table 1. to be inserted about here.]

\section{Procedure of observations}

Data were collected using observation software on a handheld personal computer. The software system used, for both collecting and analysing the data, was ObsWin (Martin et al., 2001). A Windows CE version of the program was run on a Hewlett Packard Jornada 690. This version was capable of simultaneously recording up to 46 mutually exclusive variables in real time. Each variable was coded by depressing an assigned key. All observed events were recorded as either a durational or momentary variable. Durational variables were coded 
by depressing the key to mark its onset and then again to mark its offset. Momentary variables were considered to occur within a single second time interval and so were coded by depressing the key once only.

Over 152 hours of observational data were recorded in total across all participants. On average each participant was observed for nearly seventeen hours. The mean duration of each observation session was 75 minutes. All recordings were conducted live in naturalistic environments, throughout the therapeutic week (Monday-Friday, 8.30am-5.00pm).

Participants were observed in various social setting activities as determined by their daily schedule. The observations were conducted on a quasi-random basis, as certain activities were sometimes targeted for observation.

\section{Variables recorded}

The analysed challenging behaviour variables were physical aggression, property destruction, self-injury and verbal aggression. These variables were derived by combining component behaviours that were coded using operational definitions. Physical aggression was a composite variable that comprised grabbing, hitting, kicking, pinching or punching. Self-injury was also made up of specific behaviour components, including head banging, self-hitting or self-biting. Verbal aggression was recorded according to severity, with four degrees ranging from a mild outburst to extreme verbal aggression. Only property destruction was coded at a global level, without reference to the manner in which environmental objects were damaged. The coding scheme for staff behaviours was fixed, across all participants. The staff behaviours were categorised in terms of physical and verbal responses. The coded verbal staff behaviours were: demand [an instructional prompt or command], deny [a refusal of requests], (structured) negative feedback, (structured) positive feedback, praise, question, reprimand and (social) interaction. The coded physical staff behaviours coded were: assist 
[physically facilitating participants to carry out acts] and restraint [containing the movements of participants]. Again, specific forms of staff behaviours were coded and then combined later for analysis.

\section{Interobserver agreement}

A second observer recorded data independently of the primary observer for the purpose of assessing interobserver reliability. The second observer was present during approximately $26 \%$ of the total observation time (range $17 \%$ to $55 \%$ ). Agreement between observers was calculated using the Kappa ( $\kappa$ ) coefficient (Cohen, 1960). The agreement measures were calculated on a three second interval-by-interval basis. This small tolerance level diminished the effect of dissimilar reaction times between observers (Murphy, 1987; Hall et al., 1992; Repp \& Karsh, 1994b; Emerson et al., 1996). Agreement was calculated for multiple pairs of data files. These results were summed across all files and an overall Kappa index was calculated, for both the onset and presence of the target variable. All agreement calculations were conducted by way of the specific component variables that were coded.

Using the conservative interpretations of Shrout (1998), 31\% of Kappa indices were fair $(>.4$ and $\leq .6), 46 \%$ were moderate $(>.6$ and $\leq .8)$, and $23 \%$ were substantial $(>.8)$. For the $11 \%$ of coefficients below .4 (range .28 to .39 ) an aggregated agreement value, across all participants who exhibited that particular behaviour, was calculated. All aggregated values exceeded the minimum standard of acceptability (range .49 to .84 ). The agreement coefficients of staff behaviours, calculated across all participants, were all above the minimum level of acceptability. All coefficients calculated in terms of the onset of the variable ranged from .43 to .71 and those based on its presence ranged from .62 to .96 . 
Correlational analyses were conducted to assess the likelihood of challenging behaviours and environmental events occurring concurrently. The conditional probabilities were measured using the Yule's Q index, a standardised version of the odds ratio (see, Hall \& Oliver, 1997; Oliver, Hall, \& Nixon, 1999). A Yule's Q integer greater than or equal to .5 was taken to indicate a significant co-occurrence between the challenging behaviour and the environmental event. This represented a level of association three times greater than that expected by chance. A Yule's Q value greater than or equal to .8 corresponded to a level of association five times greater than that expected by chance.

All significant concurrent associations were interpreted to ascertain the most probable antecedent to the behaviour. The interpretations were made according to an algorithm that deciphered the findings in terms of socially mediated reinforcement processes. These were conceptualised in terms of either positive social reinforcement, negative reinforcement in the form of demand escape or negative reinforcement in the form of social escape. The algorithm was designed to uncover any multiple reinforcement processes. So an outcome of several reinforcement contingencies operating simultaneously was possible. The findings were only deciphered when the challenging behaviour exhibited a significant association with at least one environment event. A conclusion was not drawn in the absence of significant concurrent associations.

Two mutually exclusive categories were devised to correspond to the relevant establishing operations of demand presentation and attention deprivation (Oliver, 1995). The event all demands comprised verbal demands and physical demands. Verbal demands related to the verbal staff behaviour demand that occurred in the absence of assist. Physical demands related to the physical staff behaviour assist that occurred in the absence of verbal demands. Given the expected overlap in the occurrence of demand and assist, it was necessary to filter out one from the other and establish an uncontaminated variable of verbal demands or 
physical demands. In this way it was possible to investigate the antecedent control of not only demand generally but also of specific aspects of demand, i.e. to evaluate whether verbal and physical demands were functionally distinct or whether they shared the same aversive qualities.

The environmental event social contact was a combined variable that comprised of all kinds of social attention that were not demand related. Thus social contact was a combination of the following staff behaviours: negative feedback, positive feedback, praise, question, reprimand, staff interaction. As way of verification, a category was created that corresponded to all forms of attention, both demand and non-demand related. This environmental event called all contact was made up of social contact and all demands. This corroborative variables was necessary since instructional demands can also be conceptualised as a form of social attention (Oliver, 1991). The environmental event all contact did not carry any such assumptions and provided a means of interpreting the results in terms of both establishing operations, i.e. demand and attention.

\section{Analysis of reinforcement contingencies}

Assertions of function that were derived from the concurrent analysis were tentative, as the findings were merely correlational. A significant co-occurrence between the target behaviour and an environmental event did not demonstrate that one variable preceded the other. This could only be corroborated by carrying out additional analyses of the reinforcement contingencies. Consequently, a sequential analysis was conducted to test whether the asserted functions could be verified by the existence of a relevant and consistent reinforcement process. An assessment of the distributive trends of the establishing operations, be it demand presentation or attention deprivation (Oliver, 1995), relative to the challenging 
behaviour was made. The temporal relationship between them was assessed so as to investigate whether the patterns of responding corresponded to a social reinforcement model.

The normalise-and-pool approach to sequential analysis was adopted (Hall \& Oliver 1992; 1997; 2000). This approach determined the conditional probabilities of the establishing operation at each percentile interval before, during and after a challenging behaviour. This calculation of probabilities at all percentile intervals required the standardisation of periods of time. The approach therefore accommodated all lengths of time between bursts of the independent variable and controlled for differences in its duration. The output was examined for specific patterns of responding consistent with a process of mutual reinforcement. For instance, four features were expected in a profile consistent with a positive reinforcement contingency (cf. Oliver, Hall, \& Murphy, 2005): (a) a diminishing likelihood of social contact leading up to the onset of the behaviour; (b) the likelihood of social contact to reach its lowest point directly before the onset of the behaviour; (c) an increasing likelihood of social contact following the onset of the behaviour; and, (d) a substantial increase in social contact following the behaviour compared to the period prior to the behaviour. For a behaviour that was negatively reinforced, by escape from demands, for instance, then the four expected profile features would be inverted: (a) an increasing likelihood of demands leading up to the onset of the behaviour; (b) the likelihood of demands to reach its highest point directly before the onset of the behaviour; (c) a decreasing likelihood of demands following the onset of the behaviour; and, (d) a substantial decrease in demands following the behaviour compared to the period prior to the behaviour.

The normalise-and-pool technique was applied wherever a challenging behaviour was significantly associated with an environmental event, as determined by the findings of the preceding concurrent analysis. However the analysis was not conducted on low frequency behaviours (i.e. $<20)$. The outcome of each sequential analysis was presented in a graph. The 
conditional probability of the establishing operation occurring at particular point was represented on the $y$ axis. The range between the minimum and maximum value was shown on this axis. The percentiles of time units in the periods before, during and after the challenging behaviour were represented on the $x$ axis. Each period was demarked in the axis. Any result that exhibited at least two features of a profile consistent with a social reinforcement model was considered to support and validate the function asserted by the concurrent analysis (Hall \& Oliver, 2000).

\section{RESULTS}

\section{Summary statistics}

All participants exhibited at least one form of challenging behaviour. Three participants engaged in all four forms. Verbal aggression was shown by all except one participant. Physical aggression and property destruction were shown by seven participants. Three participants exhibited self-injury. Summary statistics for the challenging behaviours are presented in Table 2 .

[Table 2. to be inserted about here.]

\section{Concurrent analysis}

The first aim of the study was to analyse the likelihood of challenging behaviours and environmental events occurring together. The results of the concurrent analysis are presented in Table 3. Significant associations (i.e. Yule's Q integers greater than or equal to $.5)$ are indicated by an asterisk, and values greater than or equal to .8 are further identified by two asterisks. All participants exhibited at least one topography of behaviour that was deemed to be functional. Across all participants, 21 challenging behaviours $(88 \%)$ showed a 
significant association of co-occurrence with an environmental event. No significant relationship was found for three behaviours $(12 \%)$; property destruction by participant 2 , property destruction by participant 4 and verbal aggression by participant 9 .

[Table 3. to be inserted about here.]

The complete behavioural repertoire of three participants served the same function. All the topographies exhibited by participants 3,6 and 8 were occasioned by the same antecedents and reinforced by the same stimuli. For instance, all behaviours presented by participant 3 were maintained by a process of positive reinforcement. All were significantly associated with the absence of all demands, both verbal and physical, and the absence of social contact. Significant negative associations were recorded between all demands and physical aggression (Yule's $\mathrm{Q}=-.76$ ), property destruction (Yule's $\mathrm{Q}=-.68$ ), self-injury (Yule's $\mathrm{Q}=-.90$ ) and verbal aggression (Yule's $\mathrm{Q}=-.92$ ). The associations between these behaviours and social contact were also negative and significant (Yule's Q range -.94 to -.99). The behaviours exhibited by participant 8 also showed a uniformity of function albeit with less consistency. All were contingent upon the absence of demands and were governed by a positive reinforcement process. The three behaviours exhibited by participant 6 served the same demand escape function. All demands, both verbal and physical, were considered to precede the behaviours. Significant positive associations emerged between the behaviours and all kinds of instructional contact. So, a functionally equivalent repertoire of behaviours was found for a third of participants. All the behaviours exhibited by two participants served to gain social attention while for the other participant the behavioural function was to escape demands.

Five participants exhibited a challenging behaviour topography that was maintained by two distinct reinforcement processes. These five behaviours served multiple functions. Each was attributed with both a demand escape function and an attention seeking function. 
For instance, the verbal aggression presented by participant 2 occurred during both verbal demands and also in the absence of staff contact. Verbal aggression was positively associated with verbal demand (Yule's $\mathrm{Q}=.78)$ and also negatively associated with social contact (Yule's $\mathrm{Q}=-.73$ ). The other instances of behaviours with dual functions were: participant 4's self-injury, participant 5's verbal aggression, participant 7's verbal aggression and participant 9's physical aggression. So, challenging behaviours serving more than one function were found for five participants.

Participants 2, 4, 5 and 7 exhibited multiple behaviours, within their repertoire, that served the same function. Each participant presented two challenging behaviours that were occasioned by the same antecedent and served an identical function. These pairs of behaviours were ascribed a demand escape function, as they demonstrated a significant positive association with demand intensive settings For instance, both the physical aggression and verbal aggression exhibited by participant 2 showed a significant positive association with verbal demands (Yule's $\mathrm{Q}=.90 / .78$, respectively). Physical aggression also co-occurred with physical demands (Yule's $\mathrm{Q}=.79$ ). Additionally, participant 4 and 7 also exhibited multiple behaviours maintained by positive reinforcement of social attention. These behaviours were unlikely to occur in settings that involved staff contact. Significant negative associations emerged between the challenging behaviours and non-instructional social contact, and, in some cases, instructional contact too. For instance, the self-injury and verbal aggression of participant 4 demonstrated a significant negative association with social contact (Yule's $\mathrm{Q}=-.86 /-.91$, respectively So four participants showed behaviours within the same class that served the same function, but some may be more likely to occur than others (i.e. used.) due to issues of response efficiency.

\section{$\underline{\text { Sequential analysis }}$}


The second aim of the study was to examine the sequential relationships between challenging behaviours and the appropriate environmental events. Sequential analyses were conducted to examine whether the results of the preceding concurrent analysis could be corroborated. Across all participants, thirteen challenging behaviours were attributed a demand escape function following the concurrent analysis. Five of these behaviours did not meet the criteria for analysis, i.e. they did not occur more than twenty times. These excluded behaviours were: verbal aggression by participant 2, physical aggression by participant 4 , self-injury by participant 4, property destruction by participant 6 and physical aggression by participant 9. The remaining eight behaviours were suitable for further investigation. The summary plots of these analysed behaviours are shown in Figure 1 and are labelled using the letters A to H. All eight behaviours showed an increasing level of demand prior to their onset. For all eight behaviours the highest probability of demand in the antecedent period occurred directly prior to their onset. For two behaviours $(\mathrm{D}, \mathrm{H})$ there was a decreasing level of demand following their onset. For three behaviours $(B, G, H)$ there was a substantial overall decrease in demand during the period following their offset compared to the period before their onset. In summary, one behaviour $(\mathrm{H})$ demonstrated a profile consistent with all four features of a negative social reinforcement process, three behaviours $(B, D, G)$ demonstrated three features and four behaviours (A, C, E, F) demonstrated two features.

[Figure 1. to be inserted about here.]

Across all participants, thirteen primary challenging behaviours were attributed an attention maintained function. Five of these behaviours did not occur frequently enough to be included in the study. These were: verbal aggression by participant 2, verbal aggression by participant 4, self-injury by participant 4, physical aggression by participant 8 and physical aggression by participant 9 . The summary plots for the eight behaviours that satisfied the inclusion criteria are shown in Figure 2. The plots are labelled using the letters A to H. Seven 
behaviours (A, B, C, D, E, F, G) showed a decreasing level of attention prior to their onset. For six behaviours (A, B, C, D, F, G) the lowest probability of attention in the antecedent period occurred directly prior to their onset. One behaviour $(\mathrm{G})$ exhibited a pattern of increasing attention level following onset. None of the behaviours exhibited a substantial overall increase in attention following their offset compared to the period before their onset. In summary, one behaviour $(\mathrm{G})$ demonstrated a profile consistent with three features of positive social reinforcement, five behaviours (A, B, C, D, F) demonstrated a profile consistent with two features and two behaviours $(\mathrm{E}, \mathrm{H})$ demonstrated one or zero features.

[Figure 2. to be inserted about here.]

\section{Summary}

The results from the concurrent and sequential analyses are summarised in Table 4. Across all participants, three challenging behaviours showed no significant association with an environmental event. The other 21 behaviours were attributed function from the concurrent analysis. The complete behavioural repertoire of three participants served the same function. Social attention maintained all the behaviours exhibited by participants 3 and 8 . All the behaviours maintained by participant 6 served a demand escape function. Other pairs of behaviours were also attributed with identical functions. Five participants each presented a behaviour with multiple functions, which was reinforced by both positive and negative reinforcement processes. The findings derived from the concurrent analyses were confirmed when two or more features of a reinforcement process were demonstrated by sequential analyses. Only two findings were explicitly contradicted. Verification was not possible in ten instances due to insufficient frequency required to conduct the sequential analysis. Disregarding these cases, across all evaluated findings, the concordance rate between concurrent and sequential analysis methods was $88 \%$. 
[Table 4. to be inserted about here.]

\section{DISCUSSION}

The purpose of the study was to apply a detailed descriptive analysis of clinically significant challenging behaviours shown by ABI survivors. The overall aim was to determine whether challenging behaviours exhibited by adults with ABI were functional. The temporal relationships between challenging behaviours and environmental events were explored to examine whether they adhered to a social model of reinforcement. This was achieved by using different forms of descriptive analysis methodology. Such functional assessments have been inadequately applied to the ABI population. The recording techniques adopted in this study were fine grained, extensive and encompassed a wide range of observable events. Novel recording techniques enabled various analyses to be conducted at a detailed level. Overall, findings showed a variety of concurrent and sequential relationships between challenging behaviours and environmental events.

The principle aim of the study was to establish whether environmental determinants of challenging behaviours existed. Consequently, the associations between challenging behaviours and environmental events were explored. The concurrent analysis results showed the majority of challenging behaviours $(88 \%)$ were significantly likely to co-occur with at least one environmental variable. Only three of the 24 behaviours observed did not show any significant co-occurrence with an environmental event. The presumed antecedent and the possible function of the challenging behaviours were deciphered from the results of the concurrent analysis. All participants exhibited at least one behaviour that was functional. Across all participants, no behaviours served the function of escaping social attention, a demand escape function was attributed in twelve cases and gaining social attention emerged 
as the behavioural function in thirteen cases. Five participants exhibited a challenging behaviour that was preceded by multiple antecedents and therefore considered to serve multiple functions.

Assertions of function that were derived solely from the concurrent analysis lacked validity. All such interpretations were suppositions based on correlational data. So, additional support for the function of challenging behaviours was provided by the sequential analysis. Its purpose was to examine whether appropriate sequential relationships between functional behaviours and their reinforcing consequences existed. A sequential analysis, using the normalise and pool method, was used to examine the distribution of the discriminative stimuli in relation to the occurrence of each challenging behaviour. This involved the standardisation of periods of time in order to calculate the conditional probabilities of social stimuli occurring at each percentile interval before, during and after the occurrence of challenging behaviour. A pattern of responding that exhibited two or more features expected of a social reinforcement model was considered to verify the function of behaviour. The interpretations of function based on concurrent relationships were mostly substantiated by the results of the sequential analysis. Only $8 \%$ of significant concurrent analysis findings were not explicitly supported.

The descriptive analyses conducted in this study, using both concurrent and sequential analyses, have suggested that the challenging behaviours exhibited by ABI survivors in this study served a social function and were not merely random occurrences. This finding that the challenging behaviours were socially mediated extends the limited research within the ABI literature, which have illustrated escape motivated challenging behaviours (Manchester, Hodgkinson, Pfaff, \& Nguyen, 1997; Slifer, Cataldo, \& Kurtz, 1995; Mozzoni \& Hartnedy, 2000) and attention motivated challenging behaviours (Manchester et al., 1997). One area for improvement in this study concerns the time taken to conduct the observations. It is acknowledged that conducting observations for such long durations may not be appropriate 
for clinical settings. It may well be the case that statistically meaningful findings would have emerged from shorter observation periods. Future studies should decrease the duration of time that each participant is observed.

In this study, some challenging behaviours were elicited by more than one antecedent. As such these were deemed to serve multiple functions. The self-injury of participant 4, the physical aggression exhibited by participant 9 and the verbal aggression presented by participant 3 and 7 were all reinforced by both social attention and demand removals. A potential threat to the validity of these findings was that they were not supported explicitly by a sequential analysis. In these cases sequential analyses were not conducted due to insufficient numbers. On the basis of uncorroborated correlational data, these challenging behaviours seemed to be maintained by both positive and negative reinforcers. The findings potentially support other studies that have illustrated challenging behaviours can be maintained by more than one mechanism (Durand \& Carr, 1991; Day, Horner, \& O'Neill, 1994; Kennedy, Meyer, Knowles, \& Shukla, 2000). The existence of individual topographies with differential reinforcement contingencies has important clinical implications for assessment and treatment.

The form and function of challenging behaviours presented by ABI survivors are similar to those seen in the intellectual disabilities population. This means that functional assessment methodologies, applied behaviour analysis techniques and clinical interventions used for the intellectual disabilities population could potentially be generalised to the field of neurorehabilitation. The intellectual disability literature has been increasingly focusing on the relationship between cognitive impairments and challenging behaviour. The connection between impaired cognitive functioning and challenging behaviour has not been extensively researched in the ABI literature despite being broadly accepted amongst clinicians. This is surprising given that cognitive deficits are a common consequence of brain injury (Schretlen 
\& Shapiro, 2003). For instance, reduced inhibitory control, memory loss and problem solving difficulties may be factors that increase the likelihood of challenging behaviours. Additional areas of interest in the intellectual disabilities concern the interaction between challenging behaviours and setting events, such as sleep deprivation, menstruation and mood. The ABI field may similarly benefit from more extensive research into the neurological underpinnings of challenging behaviour. These contributory factors should set the general context for functional assessments and inform ongoing neurorehabilitation efforts. The technology used in this study can not only analyse social determinants of challenging behaviours but it can also account for other neurological, cognitive and emotional factors.

Neurobehavioural approaches should also concentrate on the influence of language impairments on challenging behaviours. Within the field of intellectual disability, the link between communicative behaviours and challenging behaviours has been well established (Oliver et al., 1999). Functional communication training has been an influential intervention approach (Carr \& Durand, 1985; Durand, 1990). Functional equivalence training involves learning an adaptive communicative response that is an efficient, functionally equivalent alternative to the challenging behaviour. The alternative communicative behaviour can take the form of vocalisations (Durand et al., 1991), manual signing (Horner \& Day, 1991), picture communication symbols (Kahng, Hendrickson, \& Vu, 2000) or assistive communicative devices (Durand, 1999). Clinical strategies have been used in neurorehabilitation settings to enhance social communication skills (Godfrey \& Shum, 2000; Dahlberg et al., 2007; Shelton \& Shryock, 2007). However little empirical research has been conducted with those with severe aphasia who need compensatory communication systems (Coelho, 1987). A comprehensive descriptive analysis study can decipher the communicative function served by challenging behaviour, thereby providing an ideal starting point from which to introduce functional communication training for ABI survivors. 
In summary, in this study observational software was applied in a specialist neurobehavioural service to conduct an extensive descriptive analysis of challenging behaviours amongst adults with ABI. It was found that challenging behaviours were influenced by the environment, served a social function and reinforced by their consequences. The validity and reliability of these clinically important findings were enhanced by the detailed analysis provided by the observational software. Complex interactions between numerous variables were highlighted, through the analysis of concurrent and sequential relationships between multiple behaviours. Such a fine grained level of analysis was more readily elicited using the software than could routinely be achieved using more traditional paper-and-pen methods of assessment. This work has shown that adopting formal functional assessments within the field of neurobehavioural rehabilitation using observational software has much to commend it, and will lead to better treatment outcomes for patients. Further research should be undertaken in order to more fully appreciate the potential applications of this approach with ABI survivors. 


\section{REFERENCES}

Ager, A. \& O'May, F. (2001). Issues in the definition and implementation of "best practice" for staff delivery of interventions for challenging behaviour. Journal of Intellectual \& Developmental Disability, 26, 243-256.

Alderman, N., Knight, C., \& Morgan, C. (1997). Use of a modified version of the Overt Aggression Scale in the measurement and assessment of aggressive behaviours following brain injury. Brain Injury, 11, 503-523.

Carr, E. G. (1977). Motivation of self-injurious behavior: A review of some hypotheses. Psychological Bulletin, 84, 800-816.

Carr, E. G., \& Durand, V. M. (1985). Reducing behavior problems through functional communication training. Journal of Applied Behavior Analysis, 18, 111-126.

Carr, E. G., Newsom, C. D., \& Binkoff, J. A. (1980). Escape as a factor in the aggressive behavior of two retarded children. Journal of Applied Behavior Analysis, 13, 101117.

Coelho, C. A. (1987). Sign acquisition and use following traumatic brain injury: Case report. Archives of Physical Medicine and Rehabilitation, 68, 229-231.

Cohen, J. (1960). A coefficient of agreement for nominal scales. Educational and Psychological Measurement, 20, 37-46.

Corrigan, P. W., \& Bach, P. A. (2005). Behavioral treatment. In J. M. Silver, T. M. McAllister, \& S. C. Yudofsky (Eds.), Textbook of Traumatic Brain Injury (pp. 661-678). Arlington, VA: American Psychiatric Press. 
Dahlberg, C. A., Cusick, C. P., Hawley, L. A., Newman, J. K., Morey, C. E., Harrison-Felix, C. L., \& Whiteneck, G. G. (2007). Treatment efficacy of social communication skills training after traumatic brain injury: A randomized treatment and deferred treatment controlled trial. Archives of Physical Medicine and Rehabilitation, 88, $1561-1573$.

Day, H. M., Horner, R. H., \& O'Neill, R. E. (1994). Multiple functions of problem behaviors: Assessment and intervention. Journal of Applied Behavior Analysis, 27, 279-289.

Day, R. M., Rea, J. A., Schussler, N. G., Larsen, S. E., \& Johnson, W. L. (1988). A functionally based approach to the treatment of self-injurious behavior. Behavior Modification, 12, 565-589.

Derby, K. M., Hagopian, L., Fisher, W. W., Richman, D., Augustine, M., Fahs, A., \& Thompson, R. (2000). Functional analysis of aberrant behavior through measurement of separate response topographies. Journal of Applied Behavior Analysis, 33, 113-117.

Derby, K. M., Wacker, D. P., Peck, S., Sasso, G., Deraad, A., Berg, W., Asmus, J., \& Ulrich, S. (1994). Functional analysis of separate topographies of aberrant behavior. Journal of Applied Behavior Analysis, 27, 267-278.

Dixon, M. R., Guercio, J., Falcomata, T., Horner, M. J., Root, S., Newell, C., \& Zlomke, K. (2004). Exploring the utility of functional analysis methodology to assess and treat problematic verbal behavior in persons with acquired brain injury. Behavioral Interventions, 19, 91-102.

Durand, V. M. (1990). Severe Behavior Problems: A Functional Communication Training Approach. New York: The Guildford Press. 
Durand, V. M. (1999). Functional communication training using assistive devices: Recruiting natural communities of reinforcement. Journal of Applied Behavior Analysis, 32, 247-267.

Durand, V. M., \& Carr, E. G. (1991). Functional communication training to reduce challenging behavior: Maintenance and application in new settings. Journal of Applied Behavior Analysis, 24, 251-264.

Durand, V. M., \& Crimmins, D. B. (1988). Identifying the variables maintaining selfinjurious behavior. Journal of Autism and Developmental Disorders, 18, 99-117.

Edelson, S. M., Taubman, M. T., \& Lovaas, O. I. (1983). Some social contexts of selfdestructive behavior. Journal of Abnormal Child Psychology, 11, 299-311.

Emerson, E., Reeves, D., Thompson, S., Henderson, D., Robertson, J., \& Howard, D. (1996). Time-based lag sequential analysis and the functional assessment of challenging behaviour. Journal of Intellectual Disability Research, 40, 260-274.

Fyffe, C. E., Kahng, S., Fittro, E., \& Russell, D. (2004). Functional analysis and treatment of inappropriate sexual behavior. Journal of Applied Behavior Analysis, 37, 401404.

Godfrey, H. P. D., \& Shum, D. (2000). Executive functioning and the application of social skills following traumatic brain injury. Aphasiology, 14, 433-444.

Guess, D., \& Carr, E. (1991). Emergence and maintenance of stereotypy and selfinjury. American Journal on Mental Retardation, 96, 299-319.

Hall, S., \& Oliver, C. (1992). Differential effects of severe self-injurious behaviour on the behaviour of others. Behavioural Psychotherapy, 20, 355-365. 
Hall, S., \& Oliver, C. (1997). A graphical method to aid the sequential analysis of observational data. Behavior Research Methods Instruments \& Computers, 29, 563-573.

Hall, S., \& Oliver, C. (2000). An alternative approach to the sequential analysis of behavioral interactions. In T. Thompson, D. Felce, \& F. Symons (Eds.), Behavioral Observation: Technology and Applications in Developmental Disabilities (pp. 335-348). Baltimore, MD: Paul H. Brookes.

Halle, J. W., \& Spradlin, J. E. (1993). Identifying stimulus control of challenging behavior: Extending the analysis. In J. Reichle \& D. P. Wacker (Eds.), Communicative Alternatives to Challenging Behavior: Integrating Functional Assessment and Intervention Strategies (pp. 83-109). Baltimore, MD: Paul H. Brookes Publishing Co.

Higgins Hains, A., \& Baer, D. M. (1989). Interaction effects in multielement designs: Inevitable, desirable, and ignorable. Journal of Applied Behavior Analysis, 22, 57-69.

Horner, R. H., \& Day, H. M. (1991). The effects of response efficiency on functionally equivalent competing behaviors. Journal of Applied Behavior Analysis, 24, 719732.

Iwata, B. A., Dorsey, M. F., Slifer, K. J., Bauman, K. E., \& Richman, G. S. (1982). Toward a functional analysis of self-injury. Analysis and Intervention in Developmental Disabilities, 2, 3-20.

Iwata, B. A., Dorsey, M. F., Slifer, K. J., Bauman, K. E., \& Richman, G. S. (1994). Toward a functional analysis of self-injury (Reprinted from Analysis and Intervention in Developmental Disabilities, 1982, vol. 2, pp 3-20). Journal of Applied Behavior Analysis, 27, 197-209. 
Iwata, B. A., Pace, G. M., Kalsher, M. J., Cowdery, G. E., \& Cataldo, M. F. (1990). Experimental analysis and extinction of self-injurious escape behavior. Journal of Applied Behavior Analysis, 23, 11-27.

Iwata, B. A., Vollmer, T. R., \& Zarcone, J. R. (1990). The experimental (functional) analysis of behavior disorders: Methodology, applications, and limitations. In A. C. Repp \& N. N. Singh (Eds.), Perspectives on the Use of Nonaversive and Aversive Interventions for Persons with Developmental Disabilities (pp. 301-330). Sycamore, IL: Sycamore Publishing Company.

Kahng, S., Hendrickson, D. J., \& Vu, C. P. (2000). Comparison of single and multiple functional communication training responses for the treatment of problem behavior. Journal of Applied Behavior Analysis, 33, 321-324.

Kennedy, C. H., Meyer, K. A., Knowles, T., \& Shukla, S. (2000). Analyzing the multiple functions of stereotypical behavior for students with autism: Implications for assessment and treatment. Journal of Applied Behavior Analysis, 33, 559-571.

Kodak, T., Northup, J., \& Kelley, M. E. (2007). An evaluation of the types of attention that maintain problem behavior. Journal of Applied Behavior Analysis, 40, 167-171.

Lalli, J. S., Browder, D. M., Mace, F. C., \& Brown, D. K. (1993). Teacher use of descriptive analysis data to implement interventions to decrease students' problem behaviors. Journal of Applied Behavior Analysis, 26, 227-238.

Lerman, D. C., \& Iwata, B. A. (1993). Descriptive and experimental analyses of variables maintaining self-injurious behavior. Journal of Applied Behavior Analysis, 26, 293319. 
Lovaas, I., Newsom, C., \& Hickman, C. (1987). Self-stimulatory behavior and perceptual reinforcement. Journal of Applied Behavior Analysis, 20, 45-68.

Luiselli, J. K., Dunn, E. K., \& Pace, G. M. (2005). Antecedent assessment and intervention to reduce physical restraint (protective holding) of children and adolescents with acquired brain injury. Behavioral Interventions, 20, 51-65.

Luiselli, J. K., Pace, G. M., \& Dunn, E. K. (2003). Antecedent analysis of therapeutic restraint in children and adolescents with acquired brain injury: A descriptive study of four cases. Brain Injury, 17, 255-264.

Mace, F. C., Lalli, J. S., \& Pinter-Lalli, E. (1991). Functional analysis and treatment of aberrant behavior. Research in Developmental Disabilities, 12, 155-180.

Mace, F. C., Page, T. J., Ivancic, M. T., \& O'Brien, S. (1986). Analysis of environmental determinants of aggression and disruption in mentally retarded children. Applied Research in Mental Retardation, 7, 203-221.

Manchester, D., Hodgkinson, A., Pfaff, A., \& Nguyen, G. (1997). A non-aversive approach to reducing hospital absconding in a head-injured adolescent boy. Brain Injury, 11, 271-277.

Martin, N., Oliver, C., \& Hall, S. (2001). Obswin: Software for the collection and analysis of observational data (Version 32) [Computer software]. Birmingham, UK: University of Birmingham.

Mozzoni, M. P. (2000). Special issue: Brain injury - Preface. Behavioral Interventions, $15,153-154$. 
Mozzoni, M. P., \& Hartnedy, S. (2000). Escape and avoidance hypothesis testing using and alternating treatment design. Behavioral Interventions, 15, 269-277.

Murphy, G. (1987). Direct observation as an assessment tool in functional analysis and treatment. In J. Hogg \& N. V. Raynes (Eds.), Assessment in Mental Handicap: A Guide to Assessment Practices, Tests and Checklists (pp. 190-238). London: Chapman \& Hall.

Oliver, C. (1991). The application of analogue methodology to the functional analysis of challenging behaviour. In B.Remington (Ed.), The Challenge of Severe Mental Handicap: A Behaviour Analytic Approach (pp. 97-118). Chichester (UK): John Wiley \& Sons.

Oliver, C. (1995). Annotation: Self-injurious behaviour in children with learning disabilities: Recent advances in assessment and intervention. Journal of Child Psychology and Psychiatry and Allied Disciplines, 36, 909-927.

Oliver, C., Hall, S., \& Murphy, G. (2005). The early development of self-injurious behaviour: Evaluating the role of social reinforcement. Journal of Intellectual Disability Research, 49, 591-599.

Oliver, C., Hall, S., \& Nixon, L. (1999). A molecular to molar analysis of communicative and problem behaviors. Research in Developmental Disabilities, 20, 197-213.

Pace, G. M., Ivancic, M. T., \& Jefferson, G. (1994). Stimulus fading as treatment for obscenity in a brain-injured adult. Journal of Applied Behavior Analysis, 27, 301-305.

Persel, C. S., Persel, C. H., Ashley, M. J., \& Krych, D. K. (1997). The use of noncontingent reinforcement and contingent restraint to reduce physical aggression and selfinjurious behaviour in a traumatically brain injured adult. Brain Injury, 11, 751-760. 
Repp, A. C., Felce, D., \& Barton, L. E. (1988). Basing the treatment of stereotypic and self-injurious behaviors on hypotheses of their causes. Journal of Applied Behavior Analysis, 21, 281-289.

Repp, A. C., Harman, M. L., Felce, D., Vanacker, R., \& Karsh, K. G. (1989). Conducting behavioral assessments on computer-collected data. Behavioral Assessment, 11, 249-268.

Repp, A. C., \& Karsh, K. G. (1994a). Hypothesis-based interventions for tantrum behaviors of persons with developmental disabilities in school settings. Journal of Applied Behavior Analysis, 27, 21-31.

Repp, A. C., \& Karsh, K. G. (1994b). Laptop computer systems for data recording and contextual analysis. In T. Thompson \& D. B. Gray (Eds.), Destructive Behavior in Developmental Disabilities: Diagnosis and Treatment (pp. 83-101). Thousand Oaks, CA: Sage.

Sandman, C. A., \& Hetrick, W. P. (1995). Opiate mechanisms in self-injury. Mental Retardation and Developmental Disabilities Research Reviews, 1, 130-136.

Schretlen, D. J., \& Shapiro, A. M. (2003). A quantitative review of the effects of traumatic brain injury on cognitive functioning. International Review of Psychiatry, 15, 341349.

Shelton, C., \& Shryock, M. (2007). Effectiveness of communication/interaction strategies with patients who have neurological injuries in a rehabilitation setting. Brain Injury, $21,1259-1266$. 
Shrout, P. E. (1998). Measurement reliability and agreement in psychiatry. Statistical Methods in Medical Research, 7, 301-317.

Slifer, K. J., Cataldo, M. D., \& Kurtz, P. F. (1995). Behavioral training during acute brain trauma rehabilitation: An empirical case study. Brain Injury, 9, 585-593.

Treadwell, K. \& Page, T. J. (1996). Functional analysis: Identifying the environmental determinants of severe behavior disorders. Journal of Head Trauma Rehabilitation, 11, 62-74.

Wood, R. Ll. (1987). Brain Injury Rehabilitation: A Neurobehavioral Approach. London: Croom Helm.

Wood, R. Ll., \& Worthington, A. D. (2001). Neurobehavioural rehabilitation in practice. In R. Ll. Wood \& T. M. McMillan (Eds.), Neurobehavioural Disability and Social Handicap Following Traumatic Brain Injury (pp. 133-155). Hove: Psychology Press.

Yody, B. B., Schaub, C., Conway, J., Peters, S., Strauss, D., \& Helsinger, S. (2000). Applied behavior management and acquired brain injury: Approaches and assessment. Journal of Head Trauma Rehabilitation, 15, 1041-1060.

Zarcone, J. R., Iwata, B. A., Hughes, C. E., \& Vollmer, T. R. (1993). Momentum versus extinction effects in the treatment of self-injurious escape behavior. Journal of Applied Behavior Analysis, 26, 135-136. 


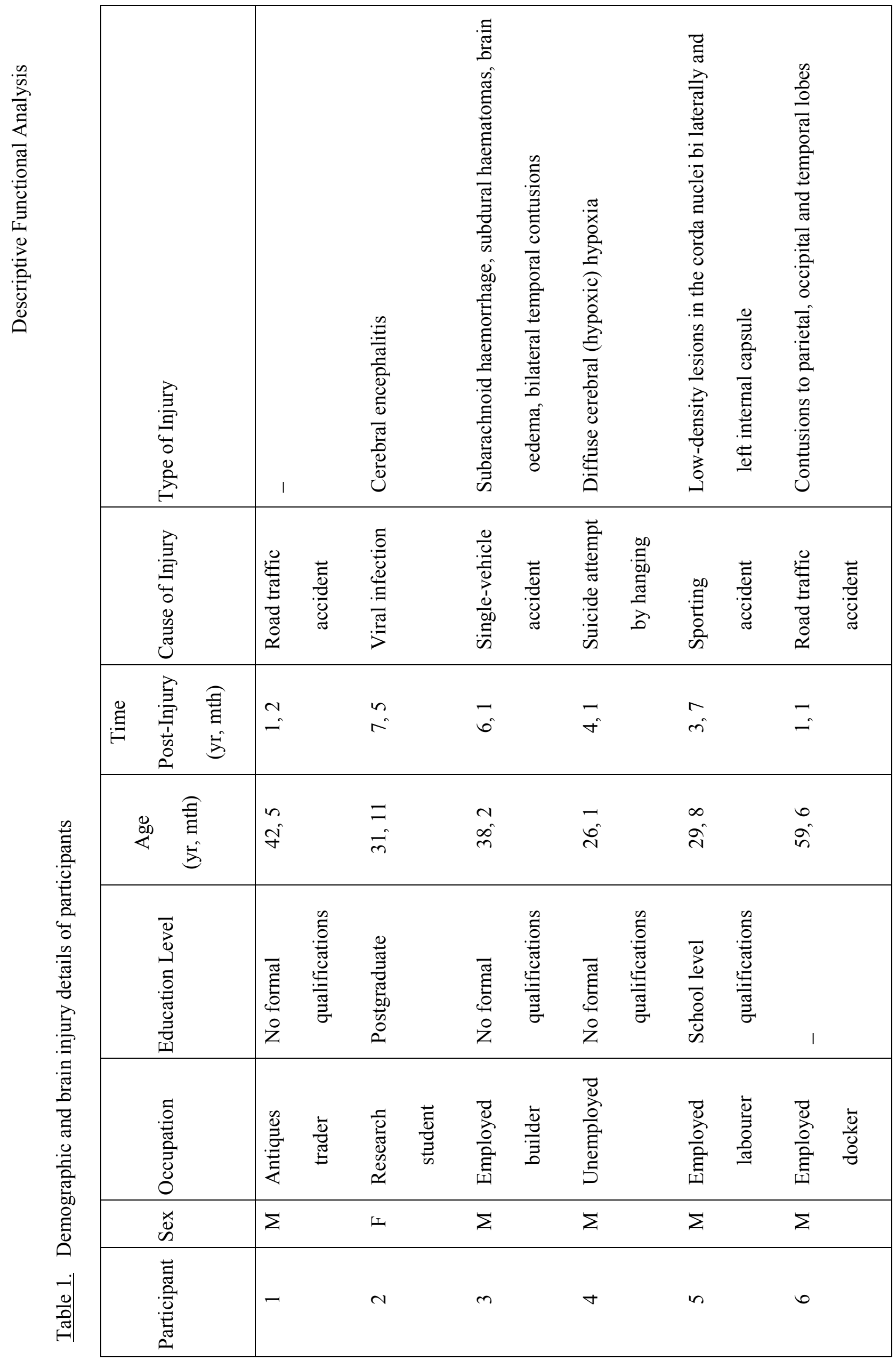




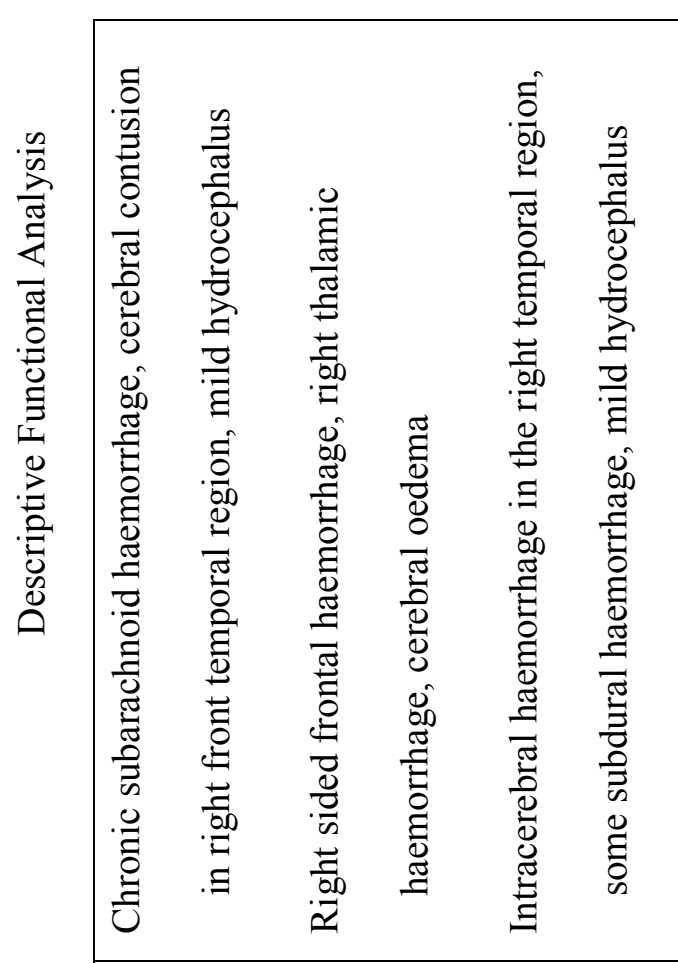

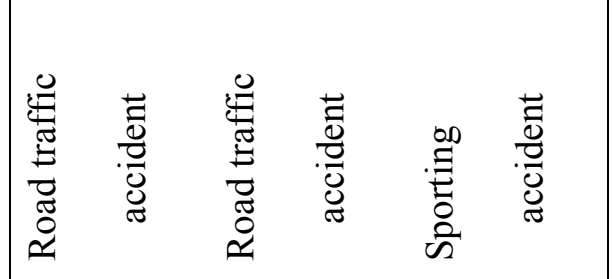

\begin{tabular}{|c|c|c|c|c|}
\hline $\begin{array}{l}\sim \\
\text { i }\end{array}$ & & m & & 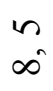 \\
\hline $\begin{array}{l}m \\
\text { m }\end{array}$ & & $\stackrel{n}{\infty}$ & & $\frac{\infty}{\hat{n}}$ \\
\hline $\begin{array}{l}\overline{\widetilde{J}} \\
\text { ב्: } \\
0 \\
0 \\
\text { Z }\end{array}$ & 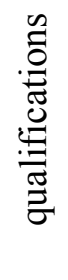 & 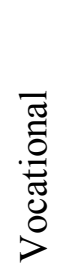 & 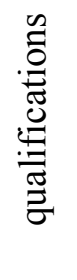 & I \\
\hline 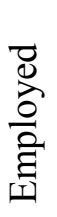 & $\begin{array}{l}\dot{\bar{\Xi}} \\
\grave{\Xi} \\
\stackrel{\Xi}{\Xi}\end{array}$ & 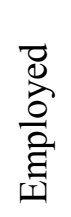 & 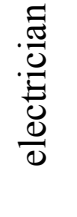 & 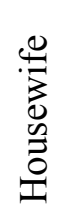 \\
\hline$\Sigma$ & & $\Sigma$ & & 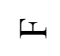 \\
\hline$r$ & & $\infty$ & & $a$ \\
\hline
\end{tabular}


Descriptive Functional Analysis

Table 2. Challenging behaviours: Summary statistics

\begin{tabular}{|c|c|c|c|c|c|c|}
\hline \multirow{2}{*}{ Participant } & \multirow{2}{*}{$\begin{array}{l}\text { Challenging } \\
\text { Behaviour }\end{array}$} & \multirow{2}{*}{$\begin{array}{l}\text { Variable } \\
\text { Type }\end{array}$} & \multirow{2}{*}{$\begin{array}{l}\text { Proportion } \\
\text { of Total } \\
\text { Time }(\%)\end{array}$} & \multirow{2}{*}{$\begin{array}{c}\text { Median } \\
\text { Duration } \\
\quad(\mathrm{sec})\end{array}$} & \multicolumn{2}{|c|}{ Frequency } \\
\hline & & & & & Total & Per Hour \\
\hline 1 & Verbal aggression & Duration & 0.17 & 1 & 79 & 6.1 \\
\hline 2 & Physical aggression & Duration & 0.09 & 1 & 49 & 2.8 \\
\hline 2 & Property destruction & Duration & 0.05 & 1 & 30 & 1.7 \\
\hline 2 & Verbal aggression & Duration & 0.19 & 4 & 21 & 1.2 \\
\hline 3 & Physical aggression & Duration & 0.94 & 1 & 174 & 18.0 \\
\hline 3 & Property destruction & Event & 0.14 & 1 & 52 & 5.4 \\
\hline 3 & Self-injury & Duration & 3.15 & 2 & 292 & 30.2 \\
\hline 3 & Verbal aggression & Duration & 16.17 & 11 & 273 & 28.2 \\
\hline 4 & Physical aggression & Duration & 0.05 & 1 & 26 & 1.0 \\
\hline 4 & Property destruction & Duration & 0.12 & 1 & 118 & 4.7 \\
\hline 4 & Self-injury & Duration & 0.04 & 1 & 25 & 1.0 \\
\hline 4 & Verbal aggression & Duration & 0.15 & 2 & 55 & 2.2 \\
\hline 5 & Property destruction & Duration & 0.32 & 3 & 44 & 2.3 \\
\hline 5 & Verbal aggression & Duration & 2.87 & 3 & 308 & 16.0 \\
\hline 6 & Physical aggression & Duration & 0.16 & 1 & 85 & 3.5 \\
\hline 6 & Property destruction & Event & 0.02 & 1 & 18 & 0.7 \\
\hline 6 & Verbal aggression & Duration & 0.49 & 1 & 291 & 12.0 \\
\hline 7 & Physical aggression & Duration & 0.29 & 1 & 146 & 7.4 \\
\hline 7 & Property destruction & Event & 0.43 & 1 & 322 & 16.4 \\
\hline 7 & Verbal aggression & Duration & 4.15 & 3 & 763 & 38.8 \\
\hline 8 & Physical aggression & Duration & 0.10 & 1 & 28 & 1.8 \\
\hline 8 & Self-injury & Duration & 0.14 & 1 & 39 & 2.6 \\
\hline 9 & Physical aggression & Duration & 0.06 & 1 & 15 & 1.7 \\
\hline 9 & Verbal aggression & Duration & 1.29 & 1 & 217 & 24.9 \\
\hline
\end{tabular}




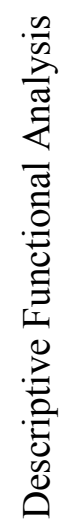

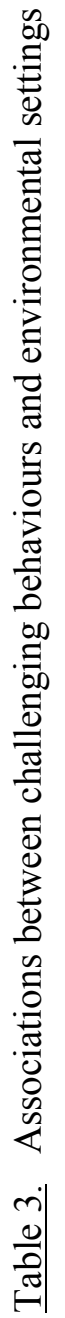




\begin{tabular}{|c|c|c|c|c|c|c|c|c|c|c|c|c|c|c|}
\hline $\begin{array}{l}\frac{0}{0} \\
\frac{0}{\sqrt{n}} \\
0 \\
0 \\
0\end{array}$ & 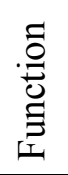 & \begin{tabular}{c}
0 \\
0 \\
II \\
1 \\
\multirow{1}{0}{} \\
0
\end{tabular} & $\begin{array}{l}\text { U } \\
\text { II } \\
\dot{1} \\
\tilde{\Xi} \\
\stackrel{0}{0}\end{array}$ & I & 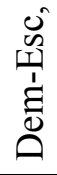 & $\begin{array}{l}\varangle \\
\text { d } \\
\text { \& }\end{array}$ & $\begin{array}{l}\mathbb{1} \\
\delta \\
0 \\
\text { is }\end{array}$ & & $\begin{array}{l}\mathbb{1} \\
\delta \\
0 \\
\text { is }\end{array}$ & & $\begin{array}{l}\mathbb{1} \\
\text { d } \\
0 \\
\text { in }\end{array}$ & & $\begin{array}{l}\varangle \\
\text { Ȯ } \\
0 \\
\text { is }\end{array}$ & \\
\hline 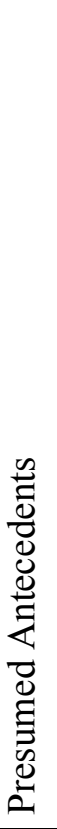 & & 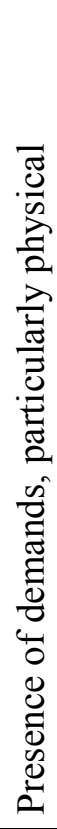 & 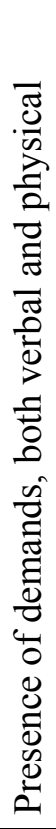 & I & 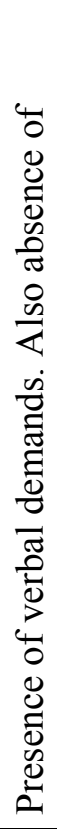 & 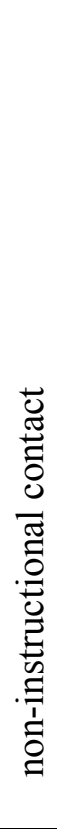 & 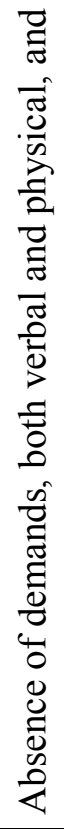 & 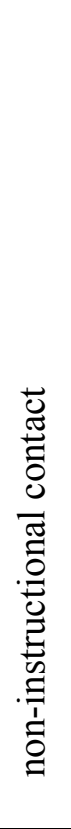 & 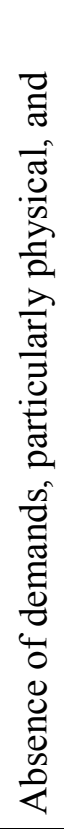 & 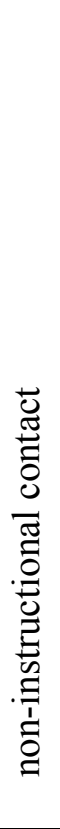 & 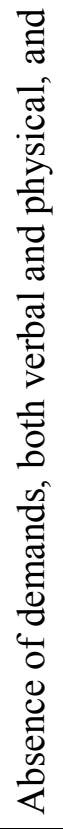 & 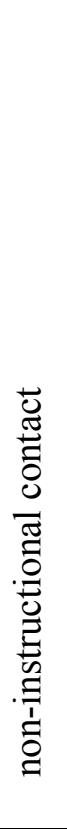 & 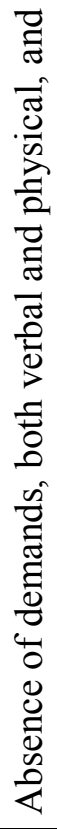 & 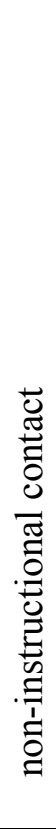 \\
\hline $\begin{array}{l}. \bar{\pi} \\
0 \\
0 \\
\tilde{n}\end{array}$ & 莽 & ?े & $\stackrel{\vartheta}{\dot{\gamma}}$ & $\underset{\text { f }}{\stackrel{g}{f}}$ & $\stackrel{*}{\stackrel{*}{\stackrel{r}{*}}}$ & & $\stackrel{*}{*}$ & & $\stackrel{*}{*}$ & & $\stackrel{*}{*}$ & & $\stackrel{*}{*}$ & \\
\hline $\bar{Z}$ & 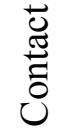 & * & $\stackrel{*}{\stackrel{*}{\curvearrowright}}$ & $\stackrel{\infty}{\mathrm{r}}$ & $\bar{\sigma}$ & & 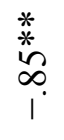 & & $\stackrel{*}{\stackrel{*}{9}}$ & & $\underset{i}{\stackrel{*}{*}}$ & & i & \\
\hline 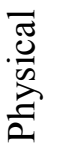 & 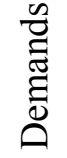 & * * & $\stackrel{*}{\stackrel{*}{2}}$ & $\stackrel{8}{0}$ & ț & & $\stackrel{*}{\stackrel{*}{*}}$ & & $\stackrel{*}{\stackrel{*}{\sim}}$ & & $\begin{array}{c}* \\
\stackrel{*}{*} \\
\stackrel{*}{\circ}\end{array}$ & & $\stackrel{*}{*} \stackrel{*}{\stackrel{*}{\alpha}}$ & \\
\hline 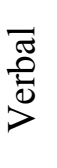 & 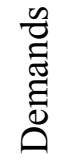 & خे & $\begin{array}{l}* \\
\stackrel{*}{*} \\
\text { ᄋ }\end{array}$ & $\stackrel{\nabla}{\forall}$ & $\stackrel{*}{\infty}$ & & $\stackrel{*}{\stackrel{*}{*}}$ & & $\stackrel{0}{0}$ & & $\stackrel{*}{*} \stackrel{*}{*}$ & & $\stackrel{*}{\stackrel{*}{o}}$ & \\
\hline $\bar{Z}$ & 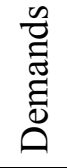 & * * & $\stackrel{*}{*} \stackrel{*}{\infty}$ & $\stackrel{0}{\stackrel{1}{1}}$ & $\stackrel{\infty}{0}$ & & $\underset{1}{\stackrel{*}{\circ}}$ & & 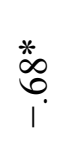 & & $\stackrel{*}{*} \stackrel{*}{\stackrel{*}{\circ}}$ & & $\stackrel{*}{\stackrel{*}{*}}$ & \\
\hline 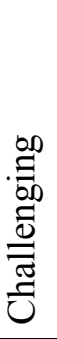 & 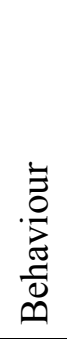 & 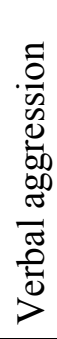 & 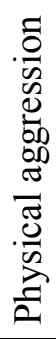 & 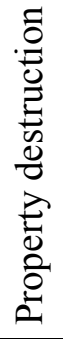 & 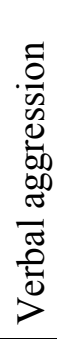 & & 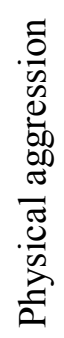 & & 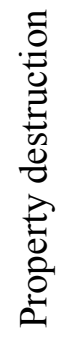 & & 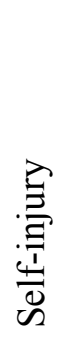 & & 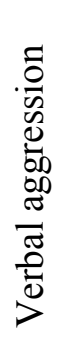 & \\
\hline 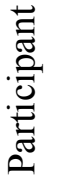 & & - & $\sim$ & $N$ & $\sim$ & & $m$ & & $m$ & & $m$ & & $m$ & \\
\hline
\end{tabular}



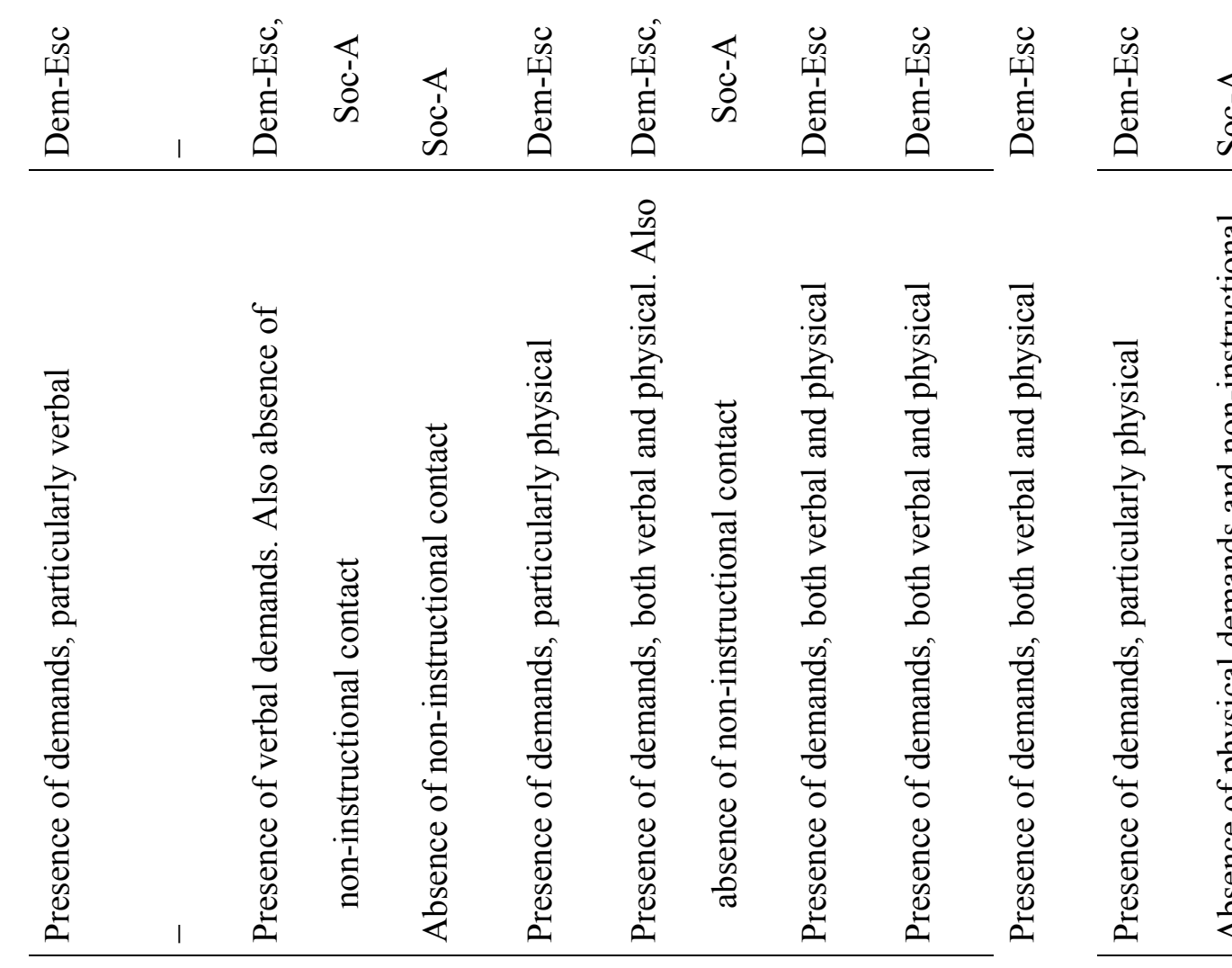

$\frac{8}{4}$

$\stackrel{0}{\gtrless}$

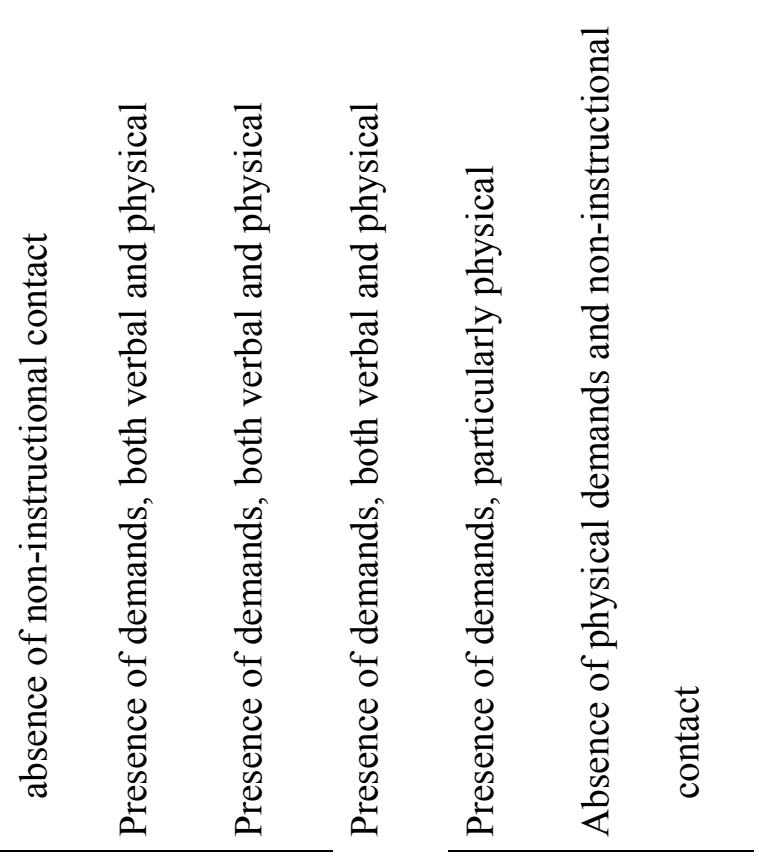

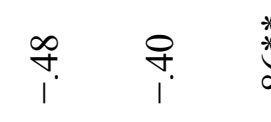

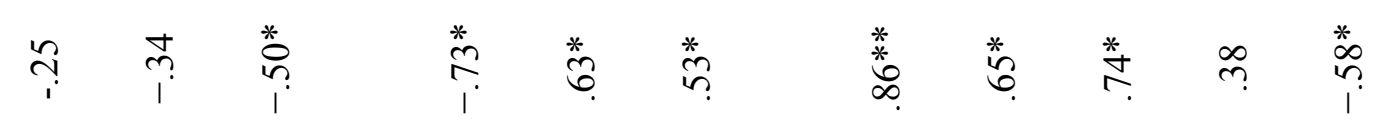

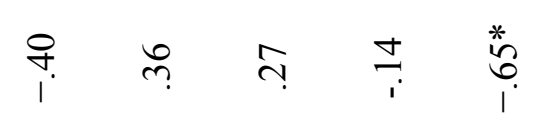

$\frac{z}{9}=\frac{1}{2}$

$$
\text { (a) }
$$

(




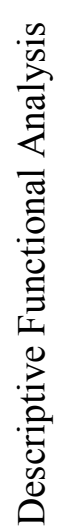
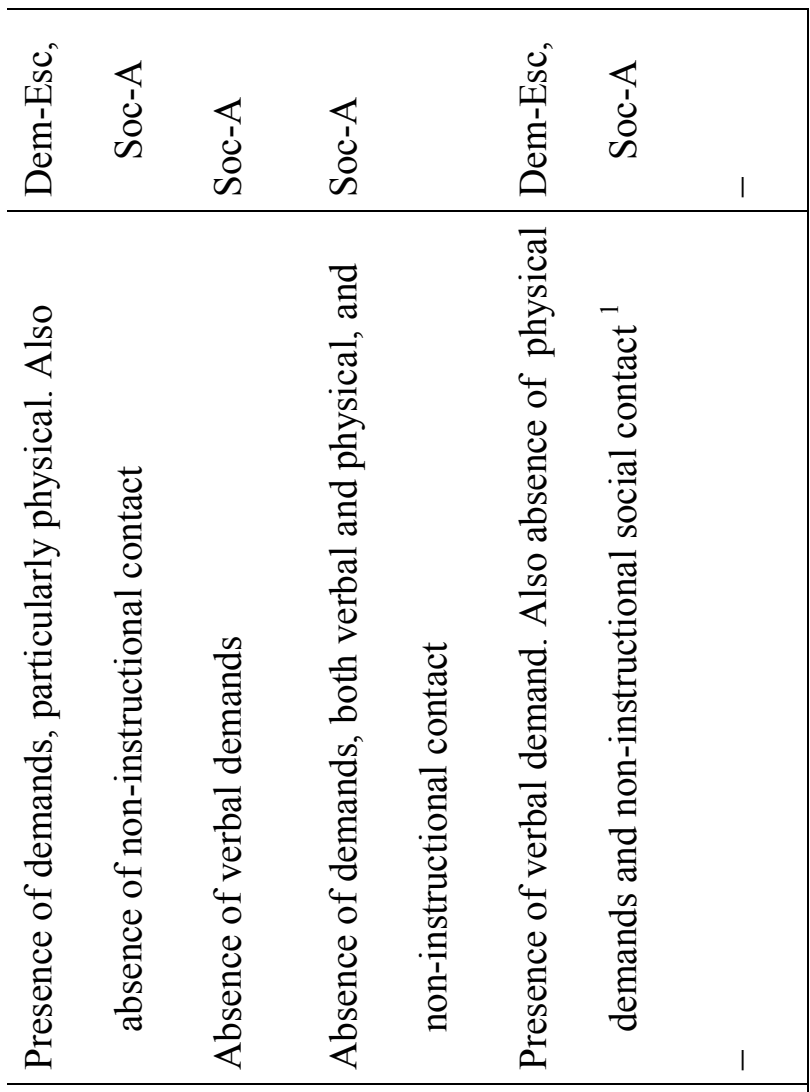

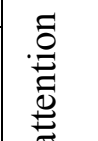

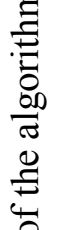

苗

$\frac{\pi}{\frac{\pi}{0}}$

.

: ठำ

II

$\begin{array}{ll}\mathbb{1} & 0 \\ 0 & \pm \\ 0 & =\end{array}$

范

氮

$\frac{\pi}{\frac{\pi}{0}} \quad$.

E 3

要

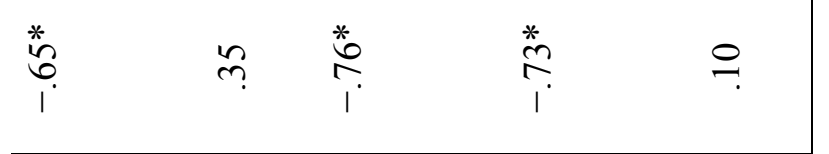

กิ กำ $\stackrel{*}{\stackrel{*}{\infty}} \quad \stackrel{*}{n} \quad=$

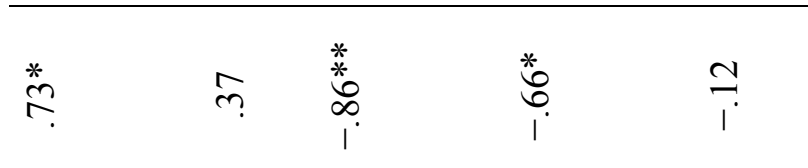

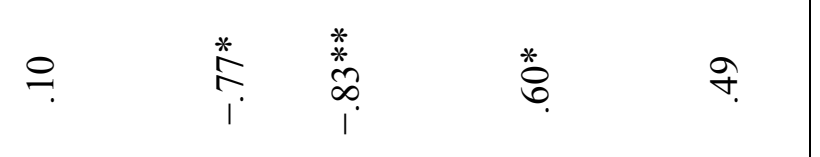

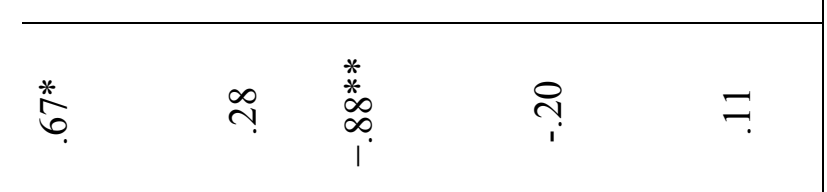

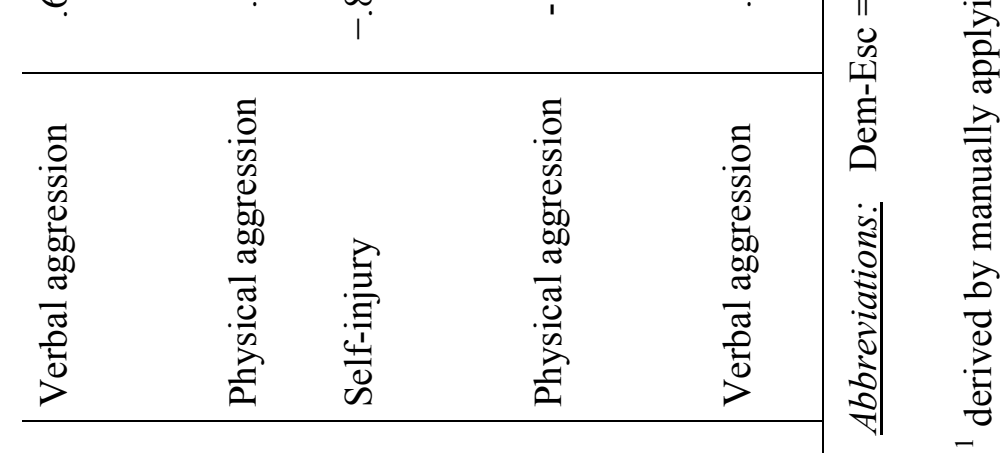

$\begin{array}{lllll}- & \infty & \infty & a & a\end{array}$

$\frac{\dot{0}}{\grave{z}}$ 


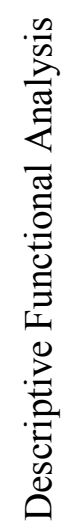

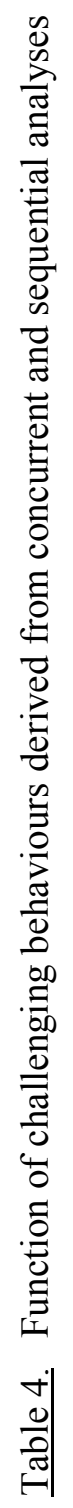




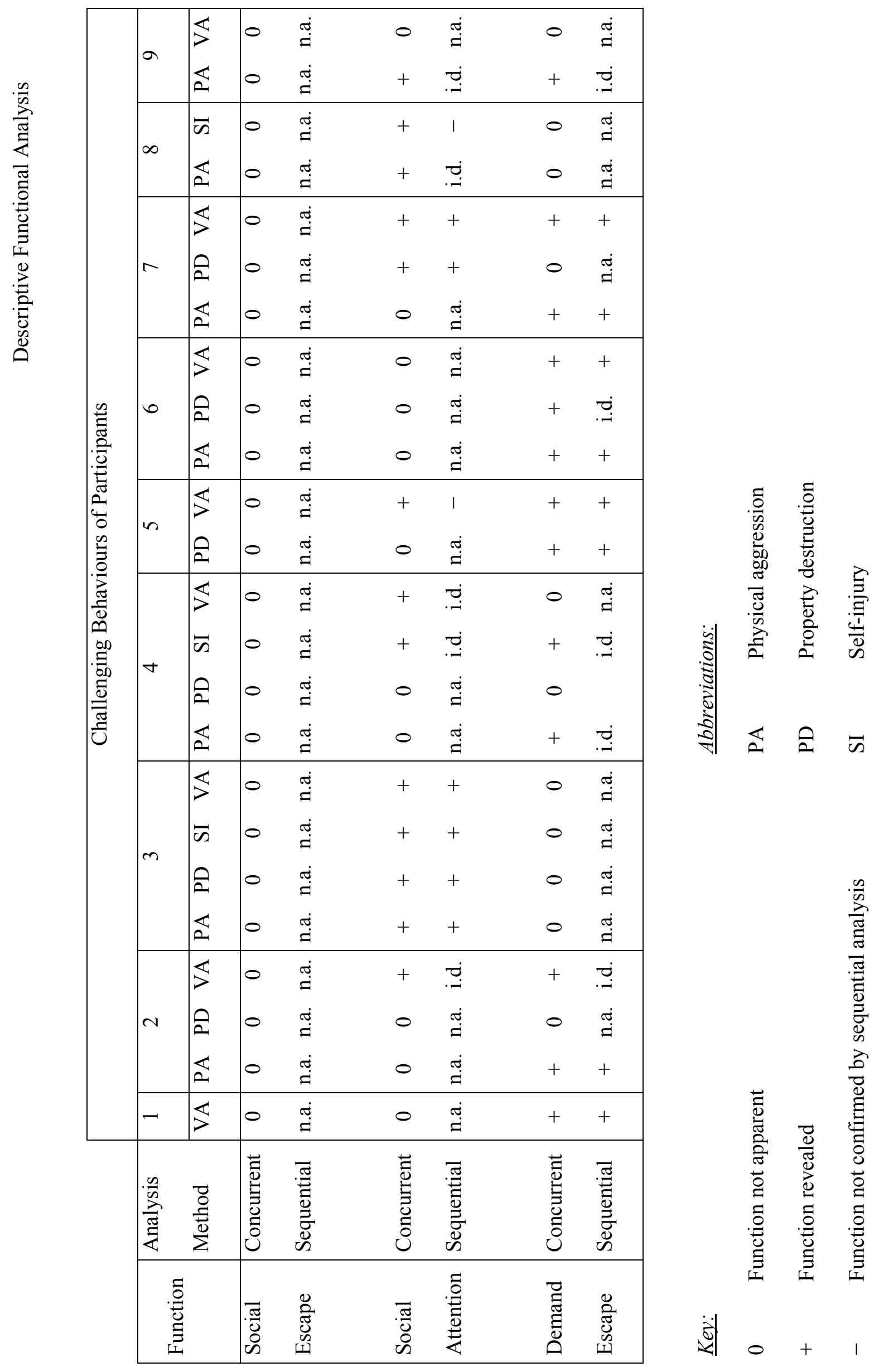




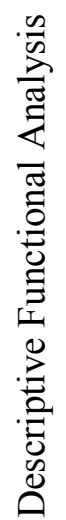

0
0
0
0
0
00
0
$\frac{\pi}{\pi}$
$\frac{\pi}{0}$
$\frac{0}{0}$

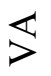

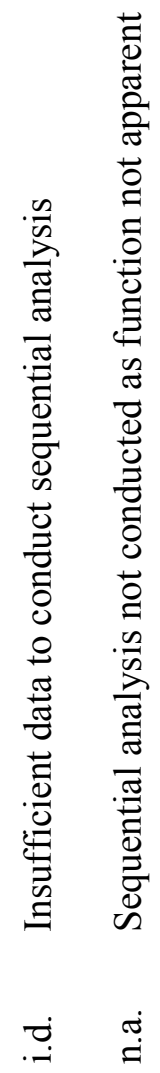


Figure 1. Probability of staff demand occurring at each percentile in the periods before, during and after the occurrence of challenging behaviour 

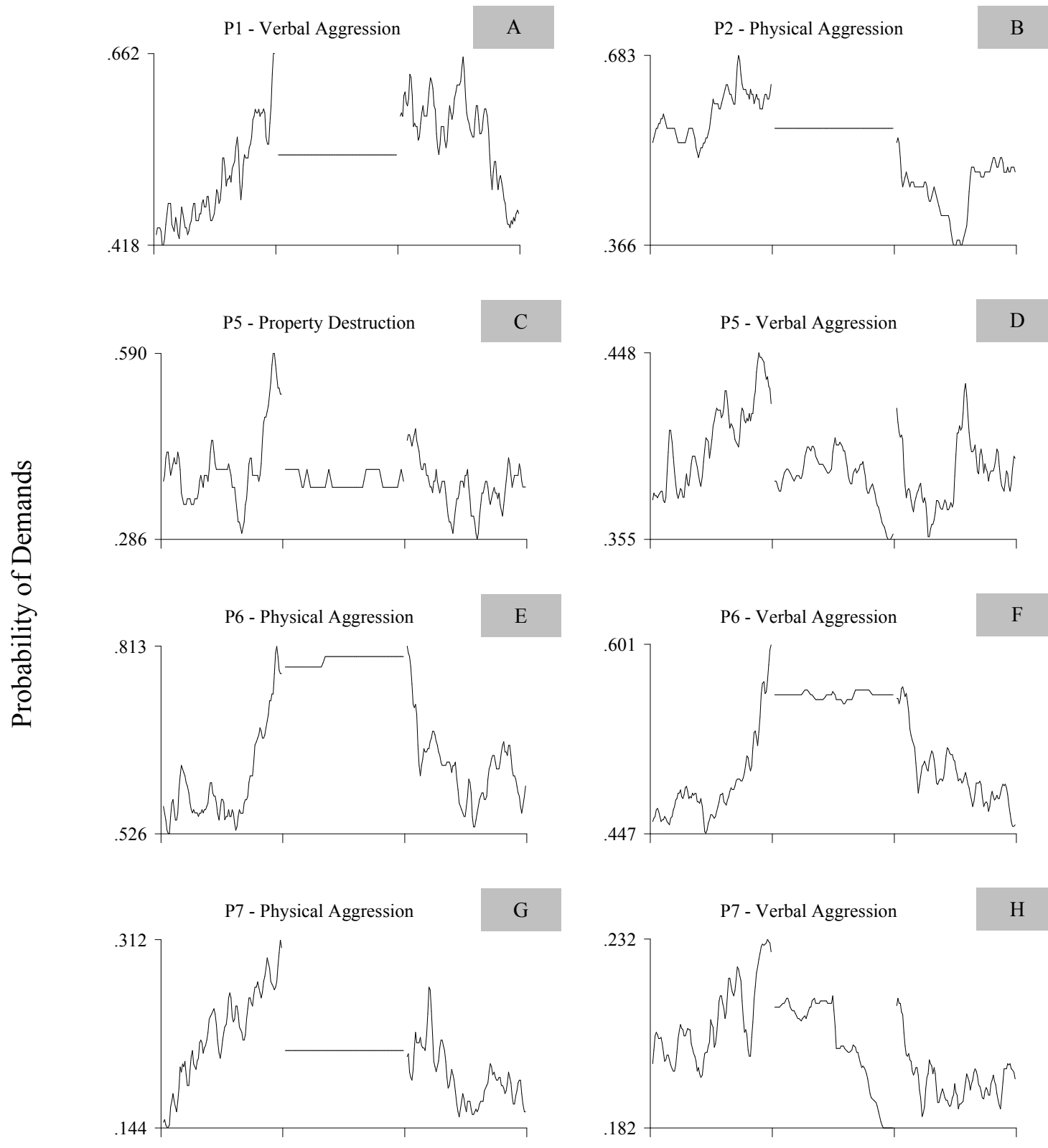

Percentiles of Time Units Before, During and After the Challenging Behaviour 
Descriptive Functional Analysis

Figure 2. Probability of staff attention occurring at each percentile in the periods before, during and after the occurrence of challenging behaviour 

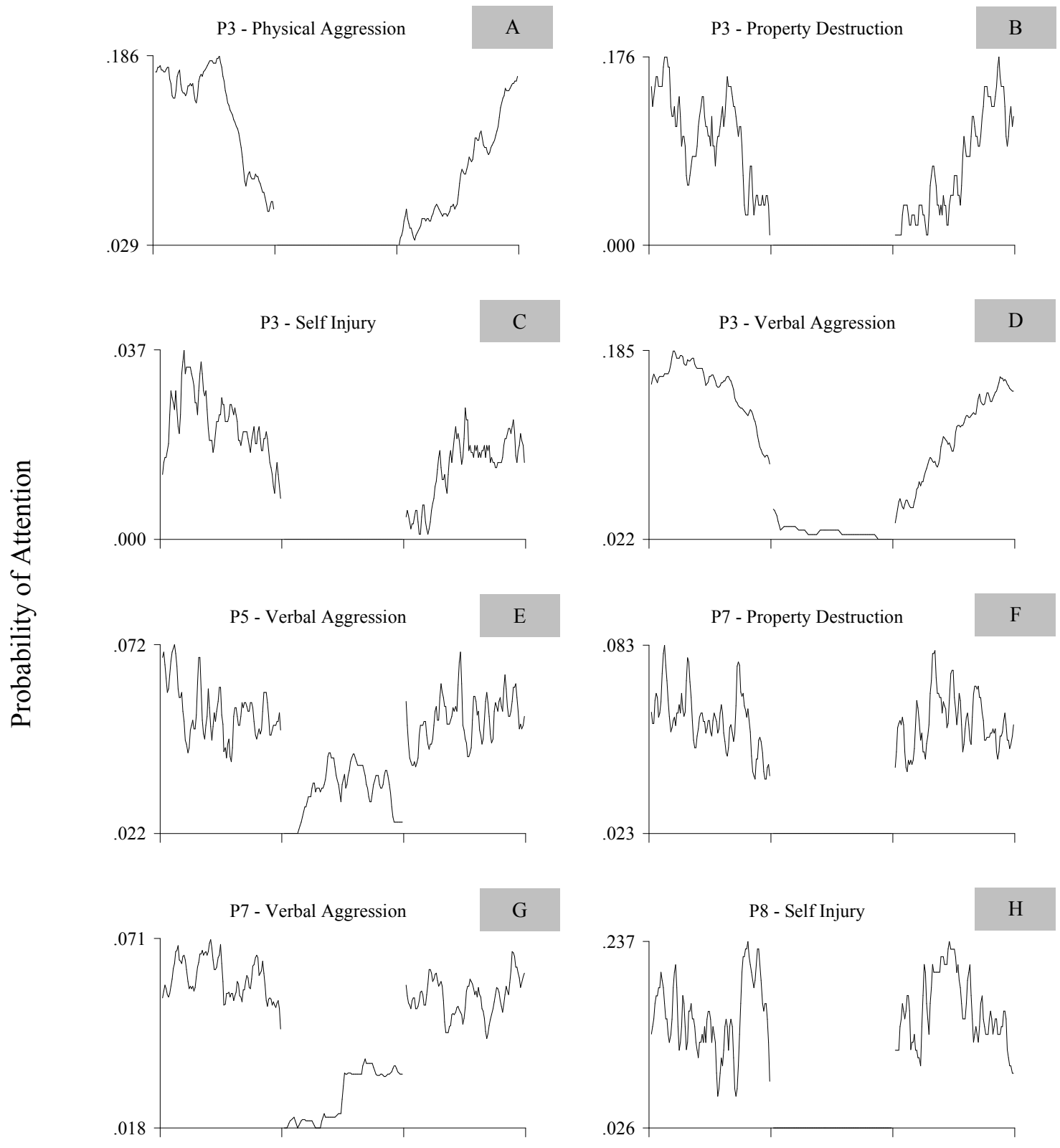

Percentiles of Time Units Before, During and After the Challenging Behaviour 